\title{
THE EFFECT OF THE SODIUM SULPHATE SOLUTION EXPOSURE ON PROPERTIES AND MECHANICAL RESISTANCE OF DIFFERENT KINDS OF RENDERS
}

\author{
MILENA PAVLÍKOVÁ*, JAROSLAV POKORNÝ*, "ONDŘEJ JANKOVSKÝ**, MARTINA ZÁLESKÁ*, \\ MARTIN VAVRO***, KAMIL SOUČEK***, ZBYŠEK PAVLÍK* \\ * Department of Materials Engineering and Chemistry, Faculty of Civil Engineering, Czech Technical University in Prague, \\ Thákurova 7, 16629 Prague 6, Czech Republic \\ ** Department of Inorganic Chemistry, Faculty of Chemical Technology, University of Chemistry and Technology, \\ Technická 5, 16628 Prague 6, Czech Republic \\ *** Department of Geomechanics and Mining Research, Institute of Geonic of the AS CR, v.v.i., \\ Studentská 1768, 70800 Ostrava - Poruba, Czech Republic \\ "E-mail: Ondrej.Jankovsky@vscht.cz
}

Submitted July 14, 2018; accepted August 24, 2018

\begin{abstract}
Keywords: Sulphate attack, Renders, Mechanical resistance, X-Ray CT, Chemically induced damage
The effect of $5 \%$ water solution of the sodium sulphate and the reference environment of distilled water on changes in mechanical resistance of the commercial dry render mixes was researched in the paper. The prism-shaped specimens cured 28 days in humid and stable conditions were immersed in water or sodium sulphate water solution. At chosen time, the particular specimens were collected, dried to constant mass, and subjected to tests. The maximum time of specimen exposure to moisture or salt action was 168 days. Within the performed experiments, length changes, mass gain, mechanical and basic properties were measured in order to reveal the effect of sulphate corrosion on researched materials. Additionally, pore size distribution measurement and X-Ray CT analysis for the most damaged render were done, in order to characterize the disruptive impact of sulphate solution on porous microstructure of lime-metakaolin-based render. The obtained data revealed the high capacity of porous space of the tested renders for salt storage. For shorter times of exposure to salt action, most of the studied renders exhibited improvement in mechanical resistance. On the other hand, after the full filling of the porous space, the evoked crystallization pressures led to the decrease in mechanical resistance and materials damage. However, one type of studied renders originally designed for restoration of salt laden masonry maintained its excellent mechanical properties even after 168 days of sulphate exposure.
\end{abstract}

\section{INTRODUCTION}

Renders represent group of construction materials used for surface finishing of buildings or their particular structures. In terms of their degradation, several decay mechanisms can be distinguished, whereas water has the major influence. Corrosive media for renders mainly includes pressure water, chloride ions, sulphate ions, carbon dioxide and other harmful acids, alkali, or salt solutions [1]. In case of pure water presence, most of the disruptive effects would not arise. On the other hand, water often becomes a transport medium for different types of salts that significantly contribute to materials deterioration [2-5]. Soluble salts may derive from acid rains or marine environment, but they are more often associated with the rising damp [6-9], and in respect to the climatic and environmental conditions of building structure negatively affect materials durability due to their physical and chemical action.

Soluble salts are considered as principal agent of decay of porous building materials and a source of great frustration to those involved in the conservation of historic and older buildings. The behaviour of salts may seem unpredictable since they can remain dormant for long periods and then suddenly become active causing damage and disfiguring historic fabric. Repeated wetting and evaporation cycles due to daily/seasonal microclimatic changes lead to the cyclic precipitation of salts and to the progressive decay of building materials, and thus whole structures [10].

Sulphate corrosion of porous building materials is caused by sulphate ions that are present for example in subsoil with high level of underground water [11], [12], in salts used for winter maintenance , and in sea water and thus in marine environments [13], where also chloride and magnesium ions are contained. The mechanism of sea water attack on construction materials is very different than what is happening in the case of pure sulphate attack [14].

The sulphate induced degradation mechanism of cement based composites depends on materials external conditions as temperature, humidity, moisture content and concentration of sulphate ions. Moisture affects especially the rate of chemical reactions, and implicates 
shape and size of the crystalline products at particular phase of sulphate corrosion. Concentration of sulphate ions affects above all the quality of corrosion products. Within the sulphate corrosion, so called sulphatation takes places, and the calcium sulphates especially in the form of gypsum $\left(\mathrm{CaSO}_{4}\right)$ are formed [15]. The gypsum formation is accompanied by the increase in volume of about $17 \%$. In this way, the porous space is filled, and in proper conditions the recrystallization takes place. The transformation of portlandite $\left(\mathrm{Ca}(\mathrm{OH})_{2}\right)$ to gypsum leads to the significant $\mathrm{pH}$ decrease that can reach value of 5.4 and that destabilizes components of cementing gel.

Another typical mineral formed within the sulphate ions action on cement-based materials, thus on $\mathrm{C}_{3} \mathrm{~A}$ (tricalcium aluminate, $3 \mathrm{CaO} \cdot \mathrm{Al}_{2} \mathrm{O}_{3}$ ), is poorly soluble ettringite $\left(3 \mathrm{CaO} \cdot \mathrm{Al}_{2} \mathrm{O}_{3} \cdot 3 \mathrm{CaSO}_{4} \cdot 32 \mathrm{H}_{2} \mathrm{O}\right)$ that can contain even 32 water molecules [16] or can be present in the form of monosulphate $\left(3 \mathrm{CaO} \cdot \mathrm{Al}_{2} \mathrm{O}_{3} \cdot \mathrm{CaSO}_{4} \cdot 11-12 \mathrm{H}_{2} \mathrm{O}\right)$. These compounds originate at $\mathrm{Ca}(\mathrm{OH})_{2}$ concentration higher than $1.1 \mathrm{~g} \cdot \mathrm{dm}^{-3}$, whereas at lower concentration are not formed. Ettringite as well as monosulphate cause high volume changes (ettringite volume is even 8 times greater compared to that of original substances) that can lead to the materials disintegration.

Thaumasite product, the third mineral produced by sulphate attack, has been increasingly found in cement based materials exposed to the sulphate ambient [17], [18]. Thaumasite is a calcium silicate carbonate sulphate hydrate $\left(\mathrm{CaSiO}_{3} \cdot \mathrm{CaCO}_{3} \cdot \mathrm{CaSO}_{4} \cdot 15 \mathrm{H}_{2} \mathrm{O}\right)$, which can coexists with ettringite, gypsum, or can occur on its own. It is clear that the non-binder thaumasite can be formed from the binder calcium silicate hydrate $(\mathrm{C}-\mathrm{S}-\mathrm{H})$ in the presence of carbonates and/or atmospheric carbon dioxide, sulphates and moisture at low temperatures, optimally $0-5^{\circ} \mathrm{C}$, where reaction conditions like relative solubilities are at their most favourable. It can be produced also from ettringite and $\mathrm{C}-\mathrm{S}-\mathrm{H}$, when carbonate and/or $\mathrm{CO}_{2}$ and sufficient water are present at the low temperatures [19]. The thaumasite formation reaction effectively ceases when the temperature rises above approx. $15^{\circ} \mathrm{C}$, but starts being produced again when the temperature is lowered below $15^{\circ} \mathrm{C}$, and especially when it lies between 0 and $5^{\circ} \mathrm{C}$. Therefore, damage of Portland cement-based materials by the formation of thaumasite is called low temperature sulphate corrosion [20]. Thaumasite is structurally similar to ettringite, and because of this, partial solid solution between the two minerals can occur resulting in ettringite/thaumasite mixed crystals.

Because of several mechanisms of sulphate induced damage of construction materials, it is important to carry out studies on the mechanical performance of materials exposed to the harmful sulphate environment. On this account, investigation of the effect of $5 \%$ water solution of the sodium sulphate and the reference environment of distilled water on changes in mechanical resistance and properties of several commercial ready-mix renders is done in the presented paper. However, one must consider that standards for testing the sulphate resistance have yet to be achieved because of varying views about the sulphate attack and its damage mechanisms, different experimental methods, inconsistent conditions between laboratory and real project conditions, and the lack of studies on change of structural properties due to the sulphate corrosion [21], [22].

\section{EXPERIMENTAL}

\section{Materials and samples preparation}

The resistance to sulphate action was researched for six commercially produced dry render mixtures (CE2-CE7), and for one specially produced render mixture with incorporated pozzolanic admixture denoted (CE1). Render CE1 (commercial name NESTOR P0/4, České lupkové závody a.s.) consisted of lime hydrate, metakaolin, silica sand of fraction $0 / 4 \mathrm{~mm}$, and water. This material was originally designed for application on stone and brick masonry, and finds use especially in renovation and reconstruction of historical buildings. Its powder density is approx. $1230 \mathrm{~kg} \cdot \mathrm{m}^{-3}$. For samples preparation, the water/dry mixture ratio was $2 / 7$; i.e., $0.28 \mathrm{~kg}$ of water was mixed with $1 \mathrm{~kg}$ of dry mixture. The commercial mixtures CE2-CE7 contained basically Portland cement, lime hydrate, and silica sand. In chosen mixtures, perlite was used for improvement of thermal insulation properties. Additionally, certain amount of the chemical admixtures was used for the modification of material properties as workability, porosity, etc. These chemical substances are secret "know how" of mortars producers, and no detail information on their composition, type, basis and dosage is available. Material CE2 (commercial name MPA 35, Baumit Ltd.) is cement-lime render with hydrophobic admixture that is designated for the machine application and can be used in interior as well as in exterior realizations. The amount of batch water was 8.61 for $40 \mathrm{~kg}$ of the dry mixture. Material CE3 (commercial name GrobPutz Maschinell, Baumit Ltd.) is cement-lime base coat render for machine application. This material is highly permeable for water vapour and is suitable for external as well as for internal use. For samples casting, 7.21 of batch water were mixed with $40 \mathrm{~kg}$ of the dry mixture. Mixture CE4 is thermal insulation render containing perlite. Its thermal conductivity is approximately $0.1 \mathrm{~W} \cdot \mathrm{m}^{-1} \cdot \mathrm{K}^{-1}$. In this case, the amount of batch water was 161 for $40 \mathrm{~kg}$ of the dry mixture. Material CE5 is renovation render Sanova Putz W (Baumit Ltd.). It is highly porous hydrophobised material (porosity $>45 \%$ ) that is used in renovation of damp and salt laden masonry, whereas the high volume of pores serves for salt accumulation. Render CE5 is also permeable for water vapour. Its water vapour resistance factor $\mu \approx 12$. The water/dry mixture ratio was 0.3 . Material CE6 (commercial name Sanova Puffer, Baumit Ltd.) 
is porous renovation render having high porosity $(\psi=55 \%)$, low water vapour resistance factor $(\mu=12)$, and low thermal conductivity $\left(\lambda=0.3 \mathrm{~W} \cdot \mathrm{m}^{-1} \cdot \mathrm{K}^{-1}\right)$. It is used as base coat under render Sanova Putz W. The water/ dry mixture ratio was 0.32 . Material CE7 is naturally white dry render mixture with limited water absorption applicable for both exterior and interior locations. The natural white colour is due to the admixture of white cement. This render is applied especially on air aerated concrete structures. The water dry mixture ratio was 0.24 . In samples preparation, the amount of batch water was used as originally recommend by renders producers and was adjusted with respect to fresh mixture workability (consistency) that was measured on flow table according to the standard EN 1015-3 [23]. The value of spreading was approx. $160 \mathrm{~mm}$, and was maintained similar for all studied renders.

The render mixtures were prepared according to EN 196-1 [24] using standard mortar mixer FORM+ TEST (Seidner \& Co. GmbH). For particular materials, 35 rod shape samples having dimensions of $40 \times 40 \times 160 \mathrm{~mm}$ were prepared. For samples casting, iron moulds surfaced by oil lubricant were used. The render mixtures were applied into the moulds in two layers, whereas the particular layers were vibrated for 30 seconds until the batch water was observed on upper surface of the samples. The samples were covered by PE foil for 24 hours. Finally, the samples were unmoulded, covered again by PE foil, and cured for 27 days in damp conditions.

\section{Sulphate corrosion}

The rod shaped samples were exposed to the con-ditions simulating the sulphate aggressive environment. For the particular materials, 20 samples were placed in a glass vessel containing $5 \%$ water solution of $\mathrm{Na}_{2} \mathrm{SO}_{4}$ (33.8 $\mathrm{g}$ of $\mathrm{SO}_{4}{ }^{2-}$ in 11 of distilled water). Remaining 15 samples were exposed to the reference environment of distilled water. See Figure 1

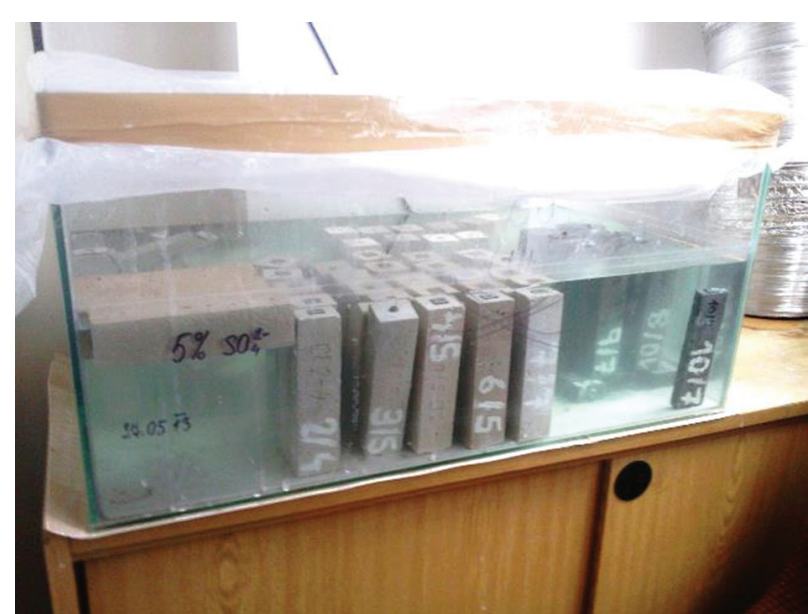

Figure 1. Tested samples in the sulphate solution environment. for the experimental arrangement. The tested samples were oriented vertically in the vessel in order to get maximal contact of the specimen surface with the salt solution. The concentration of sulphate solution was continuously monitored and maintained on the desired level. The maximal time of samples exposure to the both environments was 168 days at temperature of $23 \pm 1^{\circ} \mathrm{C}$. The selected salt concentration was based on the range of salt contents found in the analysis of case studies [25]. Similar $\mathrm{Na}_{2} \mathrm{SO}_{4}$ concentration was used for example by Lubelli et al. [26] that studied hygroscopic behavior of Dutch red bricks specimens contaminated with salts.

The effect of sulphate solution action on researched materials was analysed by both non-destructive and destructive methods. Within the non-destructive testing, the samples mass change, length change, basic structural properties and dynamic Young's modulus were measured in specific times of samples exposure to distilled water or sulphate solution. The samples length change was measured using dilatometer composed of stainless steel frame and digital drift meter ID-C (Mitutoyo) having resolution of $0.001 \mathrm{~mm}$. For the length change measurement, the samples were provided with glued metal plate for placing the drift meter rod. For basic characterization of studied materials and identification of sulphate impact on their structural changes, bulk density, specific density and total open porosity were measured. Before measurement, samples were dried in a vacuum drier at $60^{\circ} \mathrm{C}$. The bulk density was accessed using the measurement of sample sizes and its dry mass according to EN 1015-10 [27]. The specif density was measured by helium pycnometry using Pycnomatic ATC (Thermo Scientific). The total porosity was obtained on the basis of the bulk density and specific density measurement [28]. The relative expanded combined uncertainty of applied measuring method was $5 \%$.

The dynamic Young's modulus $\left(E_{\mathrm{d}}\right)$ was measured by ultrasonic pulse method using device DIO 562 working on frequency of $50 \mathrm{kHz}$ [29]. The relative expanded uncertainty of the dynamic Young's modulus test was $2 \%$. Before the ultrasonic measurements, the particular samples were dried in a vacuum drier at $60^{\circ} \mathrm{C}$ until their constant mass was reached.

Among destructive tests, flexural and compressive strength were measured. The flexural strength was determined using the procedure described in the standard EN 1015-11 [30]. The compressive strength was measured according to the same standard on the portions of prisms broken in the flexural test; the loading area was $40 \times 40 \mathrm{~mm}$. The relative expanded uncertainty of both strength tests was $1.4 \%$.

\section{Sulphate crystallization}

The progress of crystallization of sulphate corrosion products in open pore space of tested renders was studied on example of CE1 render using the X-Ray computed 
micro-tomography (X-Ray CT) and Mercury Intrusion Porosimetry (MIP). X-Ray CT method is currently widely used technique for the qualitative and quantitative analysis of internal features (e.g. pores, grains, inclusions and impurities, cracks etc.) of rocks and building materials $[31,32]$. The X-Ray CT study was conducted using XT H 225 ST industrial micro-tomographic system (Nikon Metrology NV). It is a fully automated apparatus with a rotating scanning system equipped with micro focal X-ray source which generates cone-shaped beams. Studied volumes were reconstructed using the CT Pro 3D software (Nikon Metrology NV). For subsequent imaging of sulphate products forming in the pore space of render CE1, the visualization and analysis software VGStudio MAXx 2.2 (Volume Graphics) was used.

MIP tests were done in order to explain the high and rapid damage of render CE1 in sulphate solution. For the measurement of pore size distribution, the combination of porosimeters Pascal 140 and Pascal 440 (Thermo Scientific) was used. At the evaluation of the measured data, the circular cross section of capillaries was assumed, whereas the mercury contact angle was assumed to be $130^{\circ}$. For the measurement, dried samples having weight of approx. $2 \mathrm{~g}$ were used.

\section{RESULTS AND DISCUSSION}

Time development of length changes measured for samples immersed in distilled water is presented in Figure 2. The given data represents average value from measurement on free samples, whereas the measurement was realised for samples stored in water up to 168 days. The highest length change exhibited materials CE2 and CE3, whose relative length change was approx. $0.26 \%$. The lowest length change was observed for render CE7 that yielded the maximum relative length change of $0.06 \%$. Similar low length deformation exhibited also materials CE1, CE4, CE5, and CE6.

As the length change of samples CE1 stored in sulphate solution was distinctively higher compared to strain of other examined renders, the resulting length changes were split in Figures 3, 4.

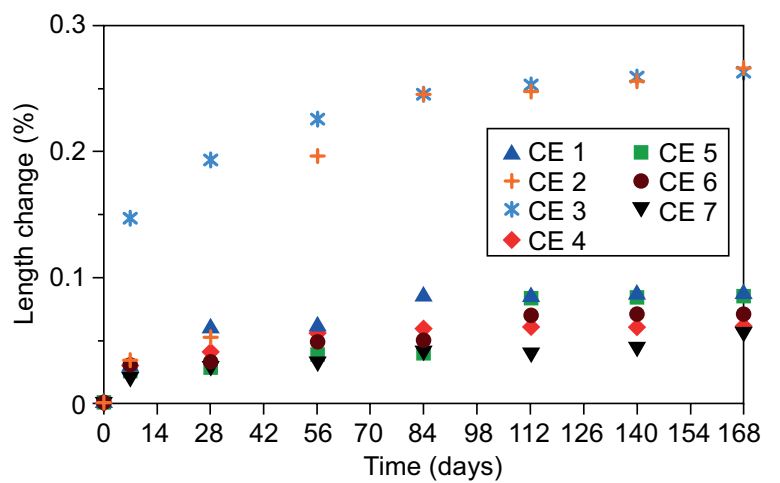

Figure 2. The relative length changes measured for renders stored in water.

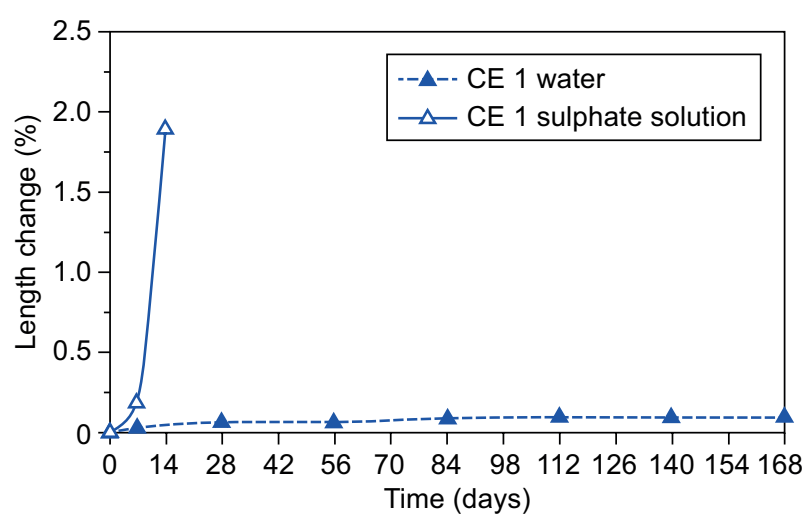

Figure 3. The relative length changes measured for render CE1 stored in sulphate solution.

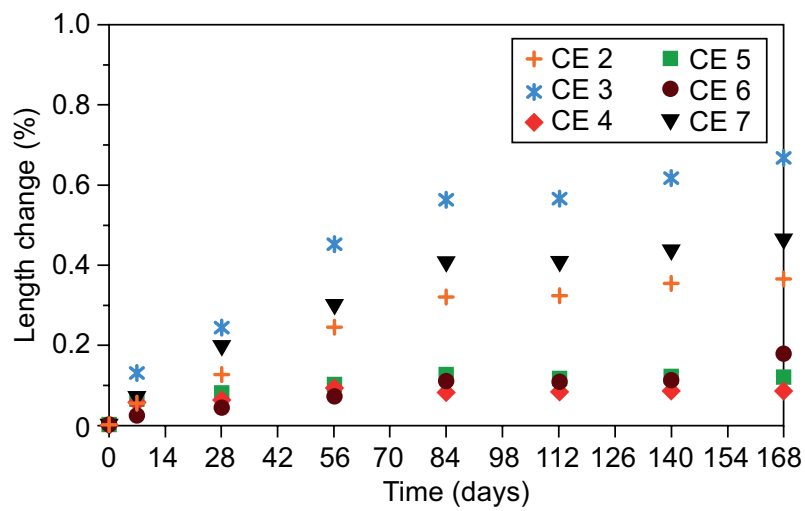

Figure 4. The relative length changes measured for renders stored in sulphate solution.

Action of $\mathrm{Na}_{2} \mathrm{SO}_{4}$ water solution on materials length changes was in a most visible for render CE1. Its maximum relative length change measured after 28 days exposure to sulphate solution was $1.91 \%$, what is approximately 20 times higher compared to data measured for CE1 samples stored in water. Additionally, during first week we observed for CE1 samples cracks formation up to the depth of $5 \mathrm{~mm}$ along the sample length and in side areas. These cracks have continuously propagated and after exceeding of 28 days of sulphate solution exposure, we were not able to perform measurements of the length and mass changes because of samples disintegration. The damage of CE1 samples induced by sulphate action is displayed in Figure 5.

The binders of render CE1 were lime hydrate and metakaolin, whereas no exact information on their exact dosage was available. However, taking into account the above given data, we assume that metakaolin is represented in low amount only, because of high amount of portlandite that reacted in sulphate environment and formed high volume crystals of gypsum. Also ettringite formation increasing the material damage can be anticipated. Similar findings were published for example by Khatib and Wild [33]. Their concluded that clay systems stabilized by lime hydrated are less binding 
than cementitious systems. Thus, these systems are more susceptible to interior volume changes due to the action of chemical agents.

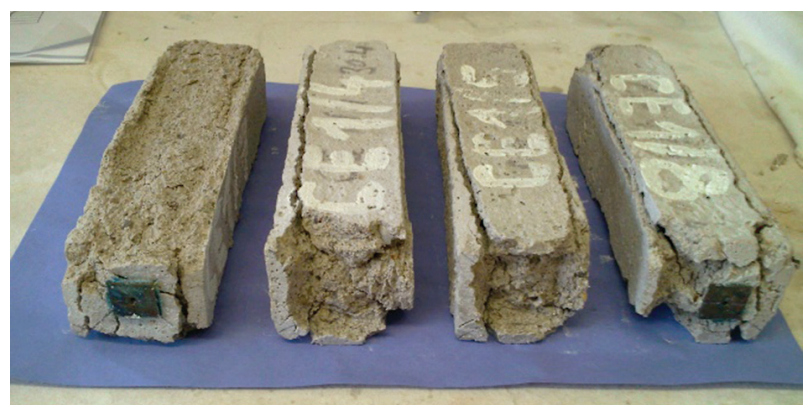

Figure 5. Disintegration of CE1 samples stored in sulphate solution.

As graphed in Figure 4, the highest length changes exhibited render CE3 (CE1 was entirely damaged), what is lime-cement base coat mortar. Its length change measured after 168 days of sulphate exposure was $0.66 \%$. This is more than 2 times higher compared to data measured for water cured samples. Material CE3 was partially damaged by formation of ettringite and gypsum, what documents also data on mechanical properties. From the practical point of view, one can assume more significant damage in long-term sulphate solution exposure. The lowest length changes exhibited material CE4. This material due to its high porosity $(81.2 \%)$ has sufficient space for accumulation of sulphate corrosion products, what resulted in relative length change of $0.09 \%$. Similar behaviour exhibited renovation renders CE5, CE6 (porosity $>50 \%$ ) that had after 168 days of sulphate solution exposure relative length changes $0.12 \%$ and $0.18 \%$, respectively. The maximum relative length changes accessed for materials CE2 and CE7 were $0.36 \%$ and $0.46 \%$.

The mass gain of materials samples exposed to the reference environment of distilled water is given in
Figure 6a. The highest increase in mass was measured for render CE4 that had at 168 days of water exposure mass increase of $12.77 \%$. This feature is evidently caused by material high porosity that allowed moisture ingress. The lowest mass increase of about $0.9 \%$ was observed for materials CE7, CE1 and CE3. Materials CE2, CE5, CE6 exhibited the increase in mass ranging from $3.35 \%$ to $7.53 \%$. This data is in agreement with measured values of the total open porosity (see below) and gives information on the water absorption capacity of investigated materials. However, part of the mass increase can be assigned to the continuous hydration of renders that continued within their water curing.

The mass changes of materials exposed to the sulphate environment are presented in Figure $6 \mathrm{~b}$. The data for render CE1 is not presented, due to the samples damage.

The highest and fastest mass gain was observed again for render CE4 that exhibited after 168 days of sulphate solution exposure mass increase of $7.98 \%$. At first sight it is quite clear that in comparison with mass increase of samples stored in water, the mass changes of samples immersed in sulphate solution are significantly lower. The structure of the $\mathrm{C}-\mathrm{S}-\mathrm{H}$ phase that forms in a stan-dard cement paste is generally believed to be either a solid solution of tobermorite and calcium hydroxide [33], or a fine-scale mixture of tobermorite and jennite [34]. The lower mass gain in case of sulphate solution curing can be explained by the differences in densities of C-S-H phases (approx. $2.32-2.78 \mathrm{~g} \cdot \mathrm{cm}^{-3}[35,36]$ ) and portlandite (approx. $2.3 \mathrm{~g} \cdot \mathrm{cm}^{-3}[37,38]$ ) compared to the low densities of sulphate corrosion products as ettringite (approx. $1.77 \mathrm{~g} \cdot \mathrm{cm}^{-3}$ ) and monosulphate $\left(1.95 \mathrm{~g} \cdot \mathrm{cm}^{-3}\right.$ ) [39]. Similarly, as soluble anhydrite has density of $2.9 \mathrm{~g} \cdot \mathrm{cm}^{-3}$ [38], density of gypsum is $2.3 \mathrm{~g} \cdot \mathrm{cm}^{-3}$ [40]. It means, with increasing $\mathrm{H}_{2} \mathrm{O}$ content, the density of sulphate corrosion products decreases. The $\mathrm{C}-\mathrm{S}-\mathrm{H}$ phases composition and density was studied e.g., by Richardson and Growes [41], Fuiji and Kondo [42],

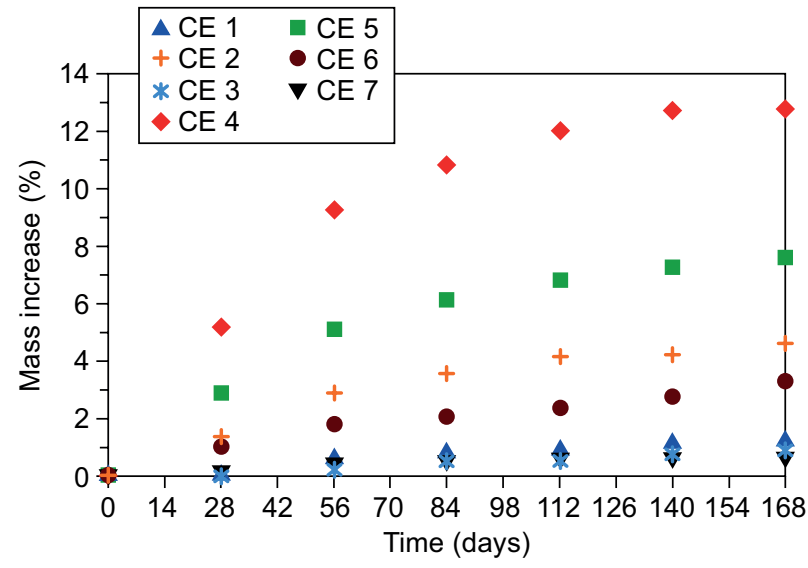

a) distilled water

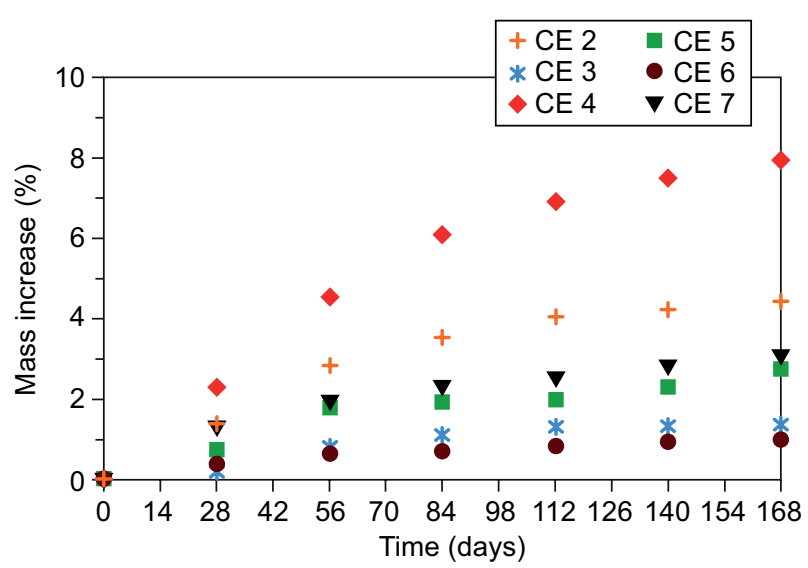

b) sulphate solution

Figure 6. Mass gain of render samples stored in distilled water (a), in sulphate solution (b). 
and Thomas et al. [43]. The data on density of chosen $\mathrm{C}-\mathrm{S}-\mathrm{H}$ phases taken from [43] is given in Table 1. This data clearly supports our explanation of the differences in mass gain of researched renders.

The above recognized materials performance is in agreement with the measured total open porosity graphed in Figures $7 \mathrm{a}, \mathrm{b}$. The values of the total open porosity were calculated from the bulk density and

Table 1. Density and composition of chosen $\mathrm{C}-\mathrm{S}-\mathrm{H}$ phases [43].

\begin{tabular}{llc}
\hline Phase & Formula & $\begin{array}{c}\text { Density } \\
\left(\mathrm{g} \cdot \mathrm{cm}^{-3}\right)\end{array}$ \\
\hline $1.1 \mathrm{~nm}$ tobermorite & $(\mathrm{CaO})_{0.75}\left(\mathrm{SiO}_{2}\right)\left(\mathrm{H}_{2} \mathrm{O}\right)_{0.92}$ & 2.48 \\
$1.4 \mathrm{~nm}$ tobermorite & $(\mathrm{CaO})_{0.83}\left(\mathrm{SiO}_{2}\right)\left(\mathrm{H}_{2} \mathrm{O}\right)_{1.33}$ & 2.23 \\
metajennite & $(\mathrm{CaO})_{1.5}\left(\mathrm{SiO}_{2}\right)\left(\mathrm{H}_{2} \mathrm{O}\right)_{1.17}$ & 2.62 \\
jennite & $(\mathrm{CaO})_{1.5}\left(\mathrm{SiO}_{2}\right)\left(\mathrm{H}_{2} \mathrm{O}\right)_{1.83}$ & 2.33 \\
\hline
\end{tabular}

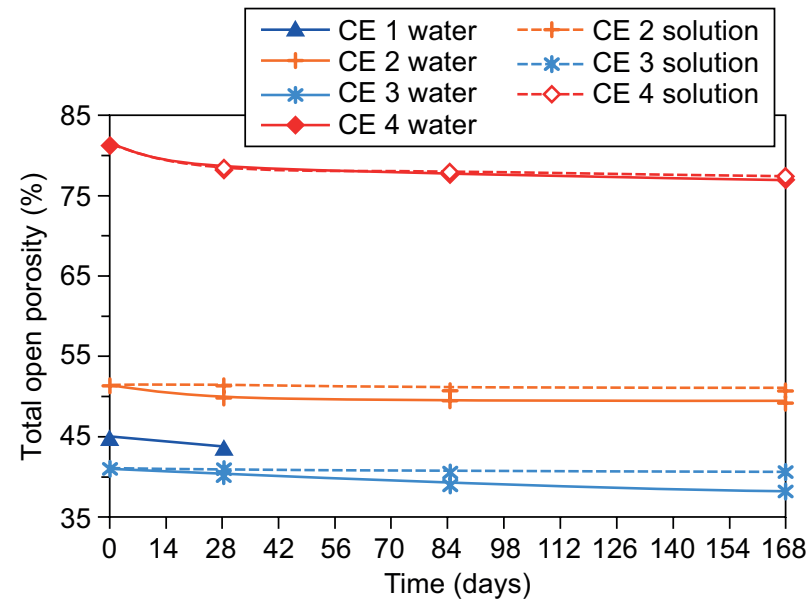

a) specific density data measured for reference samples and samples stored in water or sulphate solution for 28,84 and 168 days. Typically, with increasing time of samples exposure to water or sulphate solution, the values of total open porosity decreased, whereas the decrease of porosity was significantly lower for samples immersed in the sulphate solution except of materials CE4 and CE7. The reason for this material performance we see in ideal formation of materials microstructure within the water exposure. Material CE4 exhibited only small initial porosity decrease, whereas the negligible difference between values measured for the distilled water and the sulphate solution were found out. In case of render CE7, small decrease in porosity was identified for both environments. On the other hand, the highest decrease in total open porosity was measured for renovation render CE6, and we assigned it to the filling of the porous body of this material by the hydration and sulphate corrosion products.

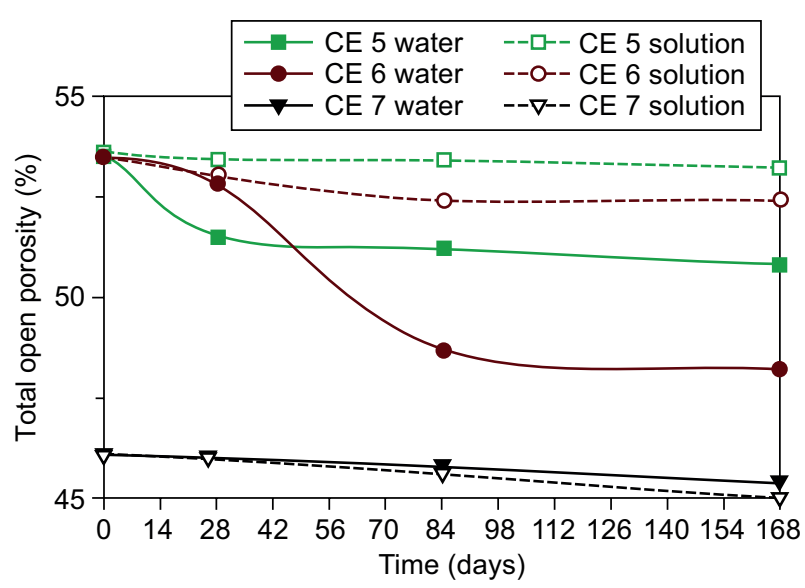

b)

Figure 7. Time development of renders total open porosity: a) CE1-CE4, b) CE5-CE7.

Table 2. Basic structural properties of researched materials - reference samples.

\begin{tabular}{|c|c|c|c|c|}
\hline Material & Environment & $\begin{array}{l}\text { Bulk density } \\
\left(\mathrm{kg} \cdot \mathrm{m}^{-3}\right)\end{array}$ & $\begin{array}{l}\text { Specific density } \\
\left(\mathrm{kg} \cdot \mathrm{m}^{-3}\right)\end{array}$ & $\begin{array}{c}\text { Total open porosity } \\
(\%)\end{array}$ \\
\hline CE 1 & \multirow{7}{*}{ Distilled water } & 1389 & 2523 & 44.9 \\
\hline CE 2 & & 1261 & 2590 & 51.3 \\
\hline CE 3 & & 1524 & 2578 & 40.9 \\
\hline CE 4 & & 370 & 1987 & 81.2 \\
\hline CE 5 & & 1144 & 2464 & 53.6 \\
\hline CE 6 & & 1101 & 2368 & 53.5 \\
\hline CE 7 & & 1372 & 2547 & 46.1 \\
\hline CE 1 & \multirow{7}{*}{$5 \% \mathrm{Na}_{2} \mathrm{SO}_{4}$} & 1440 & 2553 & 43.6 \\
\hline CE 2 & & 1297 & 2592 & 49.9 \\
\hline CE 3 & & 1542 & 2581 & 40.3 \\
\hline CE 4 & & 402 & 1950 & 78.8 \\
\hline CE 5 & & 1196 & 2464 & 51.5 \\
\hline CE 6 & & 1123 & 2379 & 52.8 \\
\hline CE 7 & & 1377 & 2551 & 46.0 \\
\hline
\end{tabular}


For basic characterization of tested materials and evaluation of the rate of renders structural changes, data on structural properties accessed for reference samples and samples stored in the both test environments for 168 days is introduced in Tables 2 and 3. All the studied materials were found to be highly porous. The highest open porosity and thus the lowest bulk density exhibited thermal insulation render CE4. Accordingly, the both renovation renders (CE5, CE6) provided by Baumit Ltd. proved their high absorption capacity for salt accumulation as their total open porosities were $>50 \%$.

The propagation of sulphate corrosion was observed also on the basis of changes in mechanical strength induced by the formation of new sulphate substances. These corrosion products can in certain extent positively affect the materials mechanical resistance. On the other hand, after the full filling of porous space, the crystallization pressures cause the decomposition and disintegration of the interior structure of composite material. The time development of the flexural strength measured for materials stored in distilled water is given in Figure 8a.
From data presented in Figure 8a, increase in the flexural strength in dependence on time of water exposure is apparent. This can be simply assigned to the progressive hydration due to the sufficient amount of water supply necessary for hydration reactions. From the quantitative point of view, the highest flexural strength was obtained for material CE3 that had after 168 days flexural strength of $3.8 \mathrm{MPa}$. On the other hand, the lowest flexural strength had plaster CE4 (0.7 MPa for 168 days of water stored samples). The low flexural strength of mortar CE4 corresponds with its high porosity and application of perlite in its composition.

The test specimens immersed in sulphate solution yielded initial improvement of the flexural strength until the structural changes caused by the formation of sulphate corrosion products appeared (see Figure $8 \mathrm{~b}$ ). The initial improvement of the flexural strength was observed up to 84 or 140 days of samples exposure to the sulphate environment depending on the type of render. Renovation render CE6 proved its applicability on salt laden masonry, since its sulphate solution exposure and

Table 2. Basic structural properties of researched materials - reference samples.

\begin{tabular}{|c|c|c|c|c|}
\hline Material & Environment & $\begin{array}{l}\text { Bulk density } \\
\qquad\left(\mathrm{kg} \cdot \mathrm{m}^{-3}\right)\end{array}$ & $\begin{array}{l}\text { Specific density } \\
\qquad\left(\mathrm{kg} \cdot \mathrm{m}^{-3}\right)\end{array}$ & $\begin{array}{c}\text { Total open porosity } \\
(\%)\end{array}$ \\
\hline CE 1 & \multirow{7}{*}{ Distilled water } & 1554 & 2533 & 38.6 \\
\hline CE 2 & & 1317 & 2601 & 49.4 \\
\hline CE 3 & & 1628 & 2626 & 38.0 \\
\hline CE 4 & & 428 & 1851 & 76.9 \\
\hline CE 5 & & 1206 & 2451 & 50.8 \\
\hline CE 6 & & 1157 & 2225 & 48.2 \\
\hline CE 7 & & 1390 & 2548 & 45.4 \\
\hline CE 1 & \multirow{7}{*}{$5 \% \mathrm{Na}_{2} \mathrm{SO}_{4}$} & - & 2588 & - \\
\hline CE 2 & & 1272 & 2597 & 51.0 \\
\hline CE 3 & & 1537 & 2584 & 40.5 \\
\hline CE 4 & & 442 & 1943 & 77.3 \\
\hline CE 5 & & 1176 & 2513 & 53.2 \\
\hline CE 6 & & 1138 & 2389 & 52.4 \\
\hline CE 7 & & 1403 & 2553 & 45.0 \\
\hline
\end{tabular}

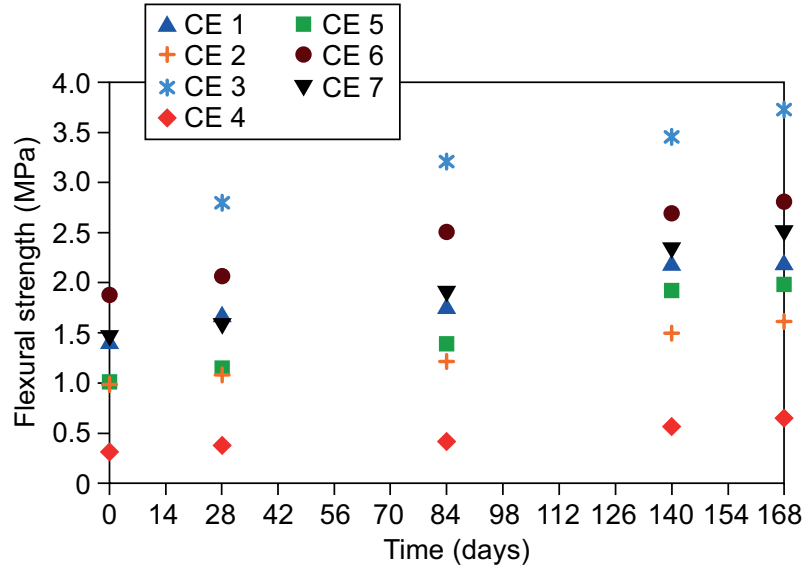

a)

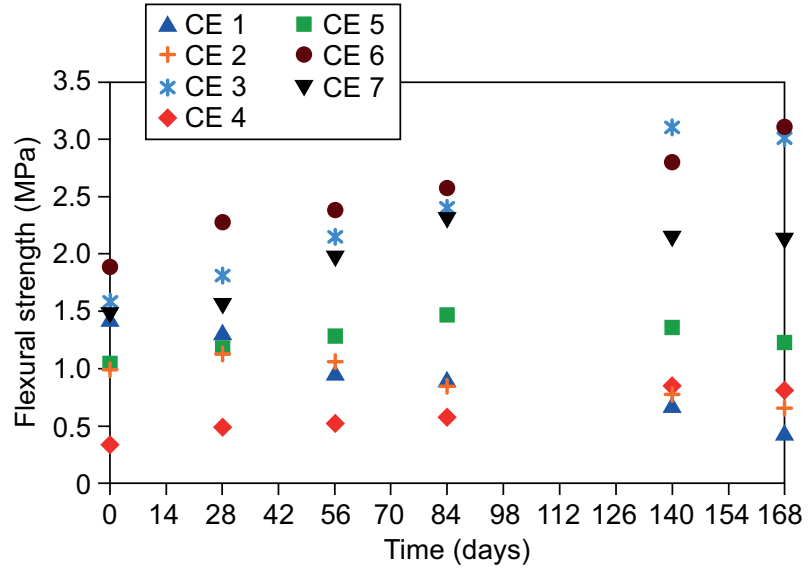

b)

Figure 8. Time development of the flexural strength - samples stored in distilled water (a), samples stored in sulphate solution (b). 
formation of corrosion products in its open porous space led to the improvement of the flexural strength for all tested samples. The lowest resistance against sulphate action exhibited mortar CE1 that lost its flexural strength already after 28 days of sulphate environment exposure. This material exhibited after storage in sulphate solution for 168 days $30 \%$ of the original flexural strength only. This feature must be taken into account in a practical application of mortar CE1, and its usage for sulphate laden structures must be avoided.

The time development of the compressive strength measured for distilled water exposed samples is presented in Figure 9a. One can observe similar behaviour of the studied renders as in the case of the flexural strength test. Here, the compressive strength systematically increased with the time of water exposure. The highest mechanical strength exhibited render CE6 that had for 168 days water cured samples compressive strength of $14.1 \mathrm{MPa}$, whereas for the reference samples without water curing we obtained value of $6.3 \mathrm{MPa}$. The lowest compressive strength, $2.3 \mathrm{MPa}$ for 168 days of water curing, had material CE4 that exhibited also only slight dependence of compressive strength on the time of water exposure.

The compressive strength data measured for samples exposed to $5 \%$ water solution of $\mathrm{Na}_{2} \mathrm{SO}_{4}$ is presented in Figure $9 b$.

The initial increase in the compressive strength is in agreement with the flexural strength data, and is caused by the increase in materials specific density. Here, not only propagation of portlandite, $\mathrm{C}-\mathrm{S}-\mathrm{H}$ and $\mathrm{C}-\mathrm{S}-\mathrm{A}-\mathrm{H}$ phases took place. Also chemical reactions of hydrated products with sulphate solution contributed in this phase to the formation of renders matrix by filling the porous space by the newly formed corrosion products. However, after 84 or 140 days of samples exposure to the sulphate solution, the porous space was fully filled by the newly formed substances, and the harmful crystallization pressures decreased the mechanical resistivity of resear- ched mortars. Similar performance of cement-based plaster observed e.g., Łukowski and Salih [44] who studied durability of PC mortars in acid and sulphate environment. The decrease in compressive strength was visible for all the studied materials except mortar CE6 that maintained its excellent mechanical properties even after 168 days exposure to the sulphate environment. The lowest resistance to the sulphate corrosion exhibited material CE1, whose samples were largely damaged by salt action. This material had after 168 days storing in sulphate environment the compressive strength of 1.7 $\mathrm{MPa}$ what represents approx. $53 \%$ decrease in the compressive strength compared to the initial reference value.

The time development of the dynamic Young's modulus measured for samples stored in distilled water is given in Figure 10a. Accordingly as in the case of the compressive and flexural strength data, the water curing supported the hydration process leading to the increase in renders density and thus to the decrease in porosity (see data presented in Figures 7a, b and Tables 2 and 3. With the increasing densities values, the dynamic Young's modulus simultaneously increased. Similar results were published e.g., by Rozière at al. [45] who tested durability of mortars and concretes made of different cements, namely PC CEM I 52.5 R, sulphate resisting PC CEM I 52.5 N PM ES, and sulphate resisting blended cement CEM III I 42.5 N PM ES. Authors stated, the resistance to sulphate attack can be improved by substitution of high- $\mathrm{C}_{3} \mathrm{~S}$ PC by $30 \%$ of fly ash.

The highest improvement and values of the dynamic Young's modulus with increasing time of water curing exhibited cement-lime render CE3 that had the maximum Young's modulus of $9.2 \mathrm{GPa}$. This material had also high compressive strength, and together with render CE6 highest flexural strength. The lowest development and values of the Young's modulus exhibited render CE4, because of its lightening by perlite and high total

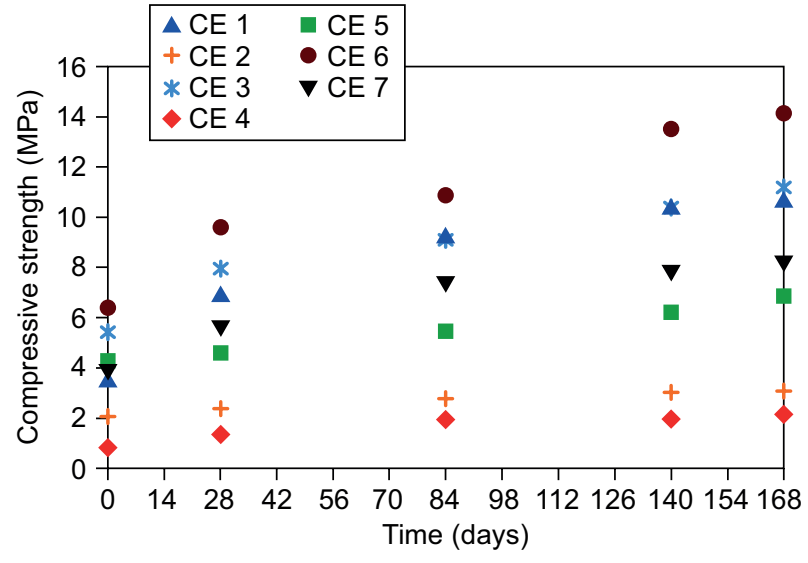

a)

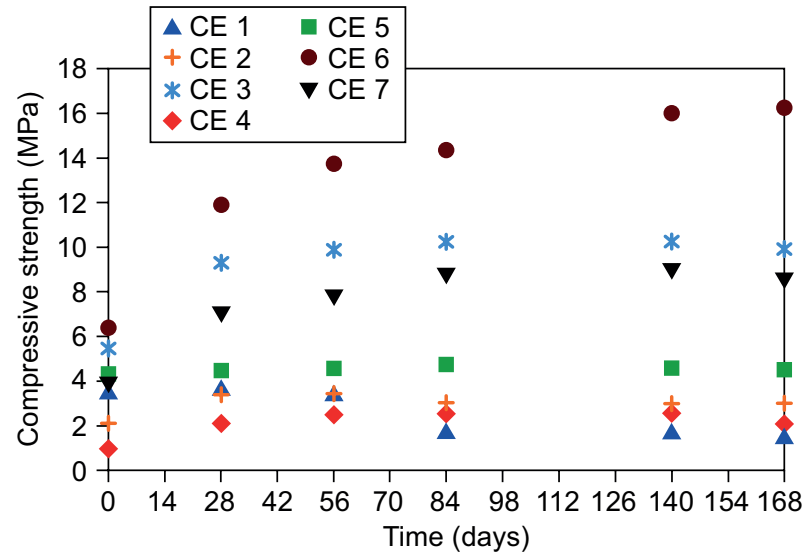

b)

Figure 9. Time development of the compressive strength - samples stored in distilled water (a) samples stored in sulphate solution (b). 
open porosity. Also in this case, the data of the Young's modulus corresponded with results of the compressive and flexural strength tests.

The data of the dynamic Young's modulus measured for samples stored in sulphate solution is given in Figure $10 \mathrm{~b}$. Here, we observed initial improvement of the Young's modulus, typically up to 56 days, and after that followed its decrease. Certain exception represents render CE3 that improves its Young's modulus from $2.8 \mathrm{GPa}$ (measured for 84 days of sulphate exposure) to 6.6 GPa (140 days). This feature is caused by crystalline new products that filled the porous space as in the case of water curing. However, after 168 days of samples storing in the sulphate solution, no increase in the Young's modulus was found, and one can assume its significant decrease in longer time of sulphate attack. The lowest values of the Young's modulus were obtained again for render $\mathrm{CE} 4$, where no measurable effect of sulphate action was identified. This material of high total open porosity is less sensitive to the changes of porous structure due to the formation of the hydration and sulphate corrosion products because of high accumulation capacity of its porous space. The results for render CE1 were not measured, because of samples damage that occurred after 28 days of sulphate solution exposure. Renders CE 2, 4, and 5 exhibited only small elasticity changes, and the measured values of the Young's modulus corresponding to specific time of samples exposure to sulphate action differed in measuring accuracy range only. From the quantitative point of view, the values of the dynamic Young's modulus were for samples stored for longer time in sulphate solution exposure significantly lower compared to the results obtained for samples cured in water.

As render CE1 exhibited the lowest resistance against sulphate attack, we performed for this material additional MIP and X-Ray CT tests in order to reveal its structural changes and identify the sulphate induced damage mechanisms. The MIP data measured for CE1 sample exposed to distilled water environment is given in Figure 11a. Based on MIP tests, one can observe development of materials microstructure and decrease in porosity due to the formation of crystallization a recrystallization products initiated by immersion of

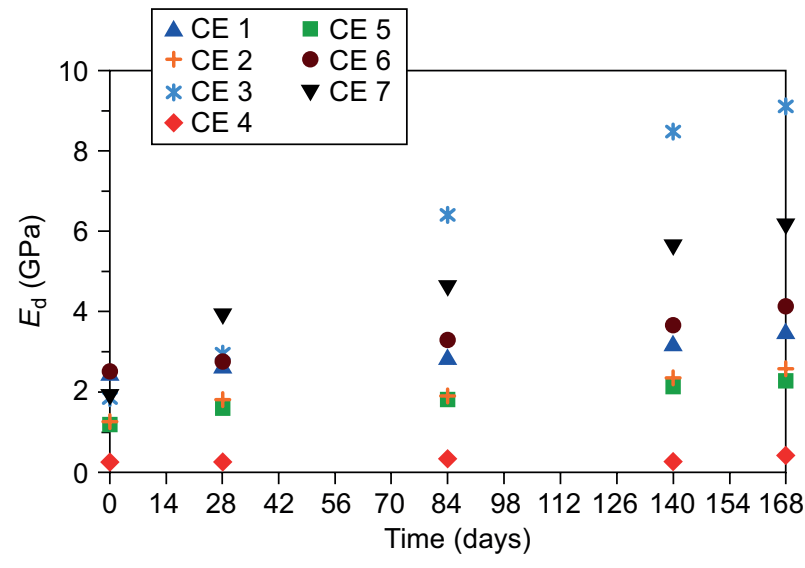

a)

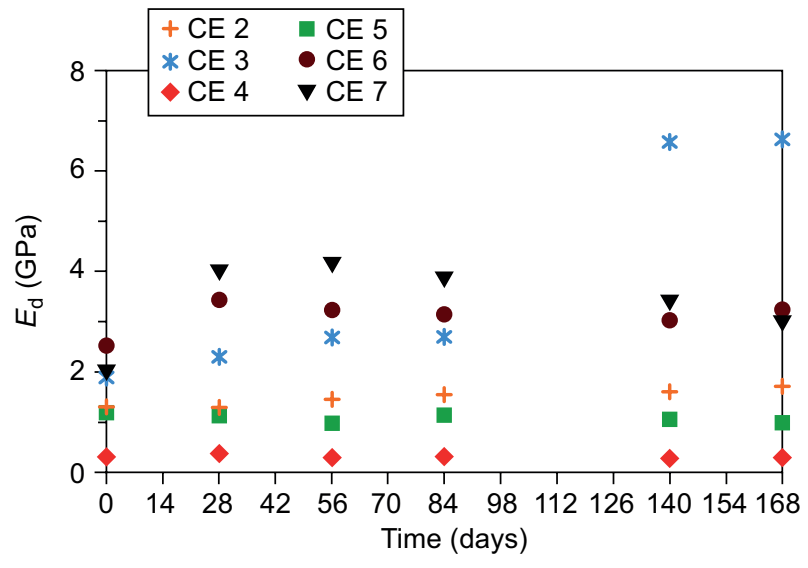

b)

Figure 10. Time development of the dynamic Young's modulus - samples stored in distilled water (a), samples stored in sulphate solution (b).

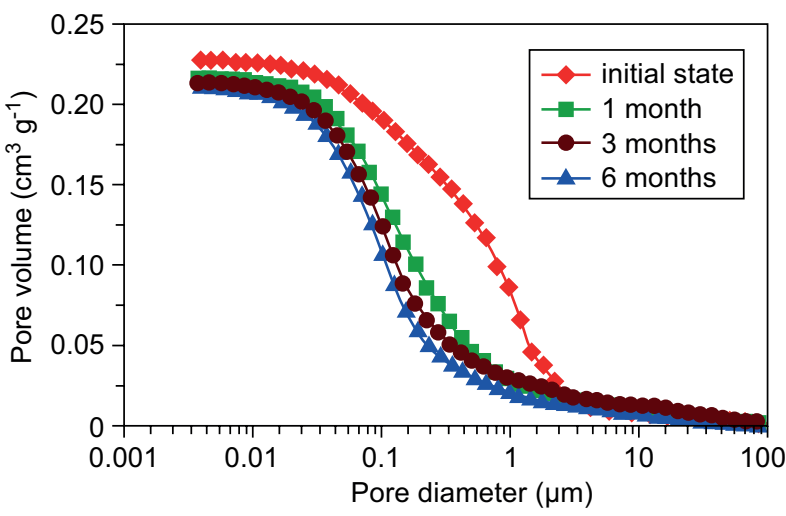

a)

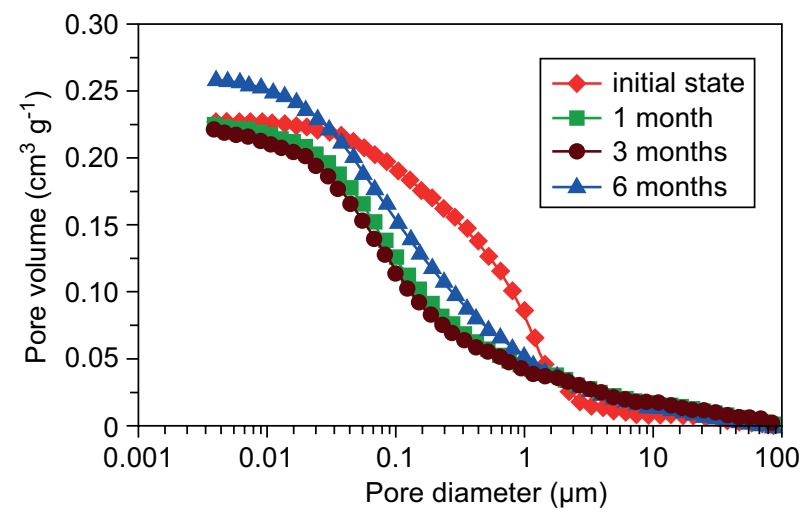

b)

Figure 11. Pore size distribution - cumulative curves, CE1 samples stored in water (a) and in sulphate solution (b). 
samples in water. The MIP data clearly explained the increase in material mechanical strength in the whole time period of water exposure. Similar materials behaviour can be anticipated also for other investigated renders.

MIP data measured for CE1 sample exposed to the sulphate environment is given in Figure 11b.

The MIP data measured for samples stored in sulphate environment is slightly different compared to those measured for water stored samples. Up to three months, the lower decrease in material porosity in pore diameter range from $0.039 \mu \mathrm{m}$ to $1.75 \mu \mathrm{m}$ than in the case of water stored samples was observed. Moreover, sulphate action led to the increase in volume of pores having diameter $>1.73 \mathrm{~mm}$. After 6 months exposure to sulphate solution, the increase in volume of pores having diameter $<1 \mathrm{~mm}$ was identified. Looking back to Figures $8 \mathrm{~b}, 9 \mathrm{~b}$, most of the studied materials exhibited improvement in mechanical properties up to 84 days of the sulphate solution exposure. After that the corrosion products disintegrated the material matrix and decreased the mechanical resistance. The initial improvement of mechanical properties we explained by continuous hydration, recrystallization and formation of sulphate corrosion products that filled partially the open porous space. However, this is not the case of render CE1 that decreased slightly its compressive strength from 56 days of sulphate exposure and flexural strength even from 28 days respectively. This behaviour of material CE1 we explain by presence of cracks formed already within 7 days of sulphate solution exposure. Since no cement was used in material CE1 composition, the slower pozzolanic reaction was not able to provide to material sufficient mechanical strength against the sulphate attack and it caused the material damage.

Formation of sulphate corrosion products in pore space of render CE1 monitored by X-Ray CT is presented in Figures 12, 13, 14. Here we identified formation of sulphate corrosion products in render porous space, whereas first the smaller air voids (Figure 15) were practically completely filled by these new mineral phases

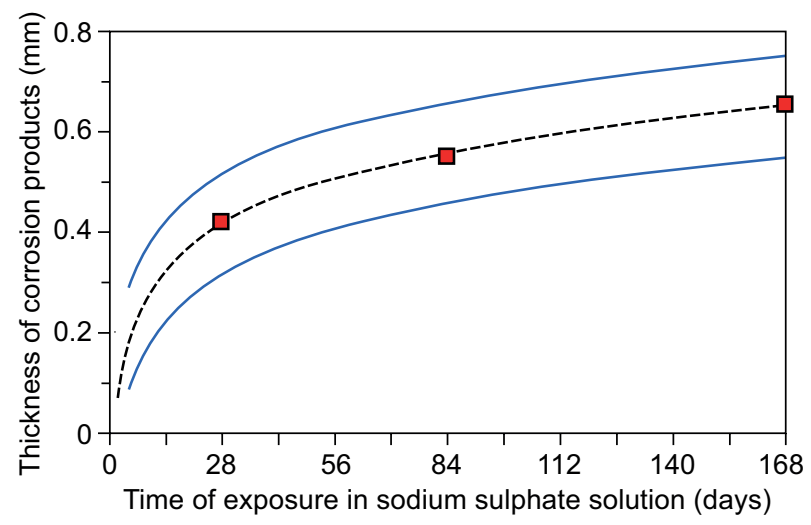

Figure 12. Time development of increasing sulphate corrosion products layer thickness in open macropores. after 168 days of sulphate action. In Figure 12, the red squares represent the arithmetic mean of 10 individual measurements of sulphate salts layer thickness, newly

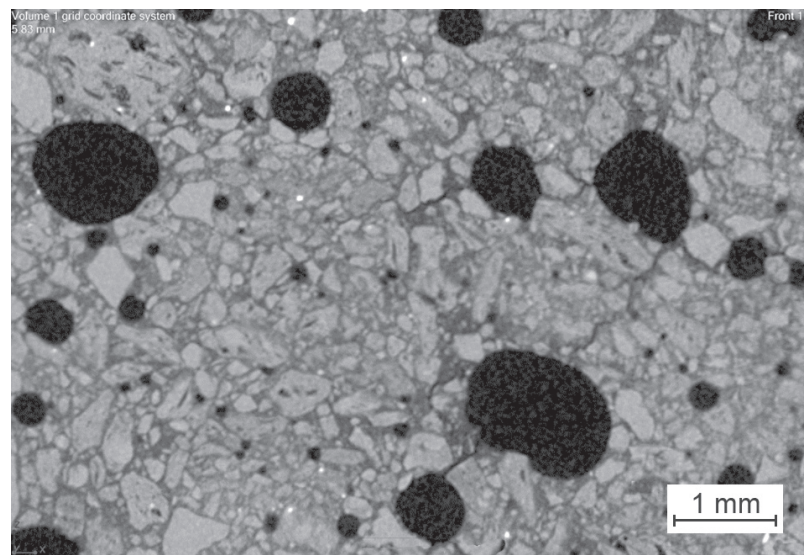

Figure 13. Large open pores in the inner structure of render CE1 - reference sample without sulphate solution exposure.

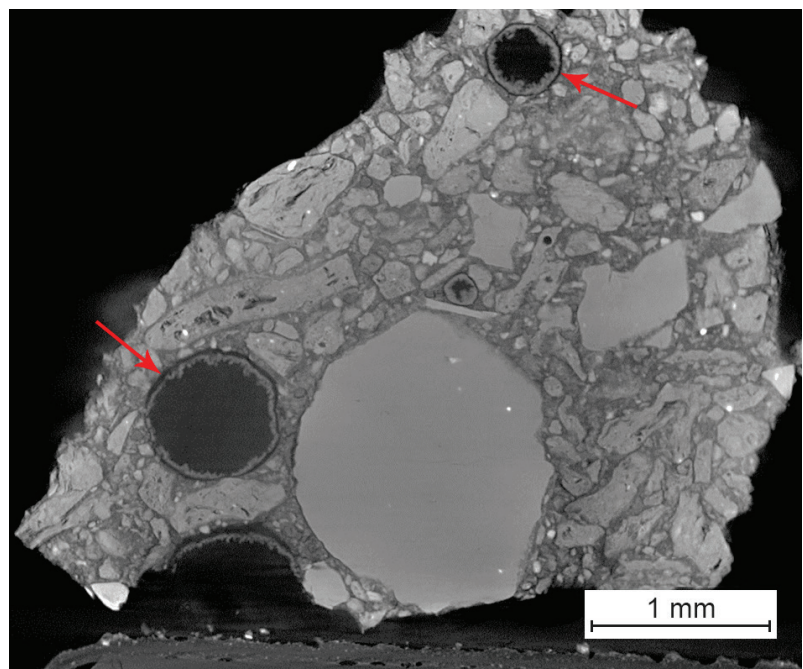

Figure 14. Macropores in render CE1 stored 168 days in sulphate environment with well-visible sulphate corrosion products layer of about $0.05 \mathrm{~mm}$ thickness.

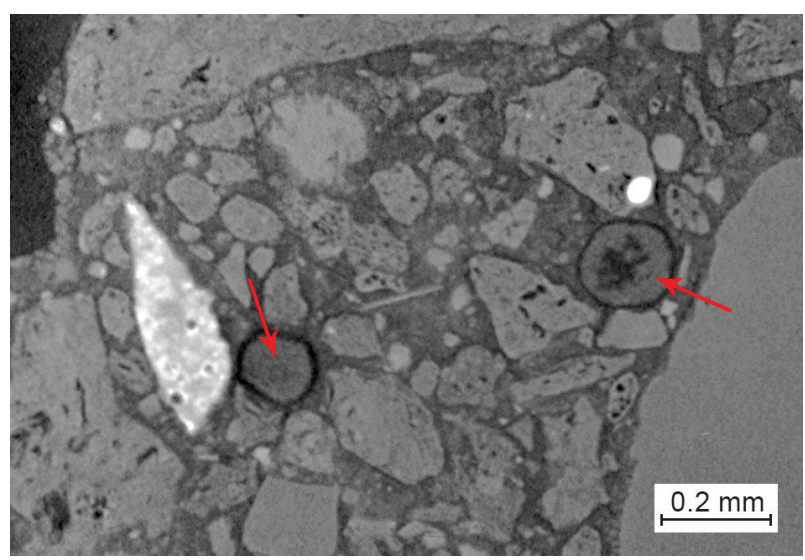

Figure 15. Smaller air voids (marked by red arrows) almost completely filled by corrosion products after 168 days of sulphate solution attack. 
formed inside the open pores with diameter of approx. 1-2 $\mathrm{mm}$. The blue continuous lines define the area of standard deviations of measured values. Looking at this figure, the progressive increase in volume of corrosion products in open pores during 28, 84 and 168 days lasting exposure in sulphate solution is well visible.

\section{CONCLUSIONS}

The main aim of the presented work was to investigate the effect of the harmful sulphate environment on the properties and behaviour of different kinds of renders prepared from the commercial dry mixtures, quantify the rate of materials damage related to sulphate corrosion products, and identify proper materials for application on salt laden substrates. The performed experimental analysis revealed the negative effect of the sulphate induced corrosion on materials mechanical parameters, and thus on their durability, even in the case of relatively short time samples exposure to the sulphate attack. Based on the obtained results and discussion presented in this study, the following conclusions can be drawn:

- For the distilled water exposure, the highest length change exhibited materials CE2 and CE3, whose relative length change was approximately $0.26 \%$. The lowest length change was observed for render CE7 that yielded the maximum relative length change of $0.06 \%$. Similar low length deformation exhibited also materials CE1, CE4, CE5, and CE6.

- The relative length changes measured for samples stored in sulphate solution were significantly higher compared to the results obtained for the distilled water exposed samples. Sulphate action on materials length changes was in a most visible for render CE1. Here, the maximum relative length change measured after 28 days exposure to sulphate solution was $1.91 \%$, what is approximately 20 times higher compared to the data measured for CE1 samples stored in water.

- Except render CE1, the highest sulphate induced length changes exhibited render CE3, what is limecement based coat render. Its length change measured for samples stored in sulphate solution for 168 days was $0.66 \%$. This is more than 2 times higher compared to the data measured for water cured samples.

- The lowest length changes in sulphate solution exhibited material CE4. This material due to its high porosity $(81.2 \%)$ has sufficient space for accumulation of sulphate corrosion products, what resulted in the relative length change of $0.09 \%$. Slightly higher length changes exhibited renovation renders CE5, CE6 (porosity $>50 \%$ ) that had relative length changes 0.12 and $0.18 \%$ respectively.

- The mass increase of samples stored in the sulphate solution was significantly lower compared to the mass gain measured for water exposed samples. Although the materials porosity is crucial parameter limiting the water or/salt solution absorption, the differences in mass gain between samples exposed to the tested environments pointed out to the formation of sulphate corrosion products. The lower mass gain in case of sulphate curing was explained by the differences in densities of C-S-H phases and portlandite compared to the low densities of sulphate corrosion products as ettringite and monosulphate.

- Due to the disintegration of CE1 samples stored in sulphate solution, the mass gain was not measured. The material damage was caused by the production of high volume of gypsum that was formed within the reaction of portlandite and sulphate ions dissolved in water.

- The mass and length changes data is in agreement with the measured values of the total open porosity, whose values decreased systematically less in case of the sulphate solution exposure than in water curing. This effect we assigned to the ideal formation of materials microstructure within the water exposure that allowed prolongation of hydration process and subsequent recrystallization of hydrated products.

- We recognized initial drop in the porosity for all studied materials stored in both environments. The highest decrease in the total open porosity was measured for renovation render CE6, and we assigned it to the filling of the porous body of this material by the hydration and sulphate corrosion products.

- The water storage led to the significant improvement of the mechanical resistance of tested materials that was characterized by the flexural strength, compressive strength, and the dynamic Young's modulus tests.

- The sulphate solution exposure yielded initial improvement of the flexural strength until the structural changes caused by formation of sulphate corrosion products appeared. Renovation render CE6 proved its applicability on salt laden masonry, since its sulphate solution exposure and formation of corrosion products in its open porous space led to the improvement of the flexural strength for all tested samples. The lowest resistance to sulphate action exhibited mortar CE1 that lost its flexural strength already after 28 days of sulphate environment exposure. This material exhibited after storing for 168 days in sulphate solution $30 \%$ of the original flexural strength only.

- The compressive strength data measured for the specific times of water and sulphate exposure exhibited similar behaviour as results of the flexural strength test. After 84 or 140 days of samples exposure to sulphate solution, the porous space was fully filled by the newly formed substances, and the harmful crystallization pressures of corrosion products disintegrated the materials structure and thus decreased 
their compressive strength. This feature was visible for all studied materials except for mortar CE6 that maintained its excellent mechanical properties even after 168 days of exposure to sulphate environment. The lowest resistance to sulphate corrosion exhibited material CE1, whose samples were largely damaged by a salt action.

- Due to the continuous hydration in water, the dynamic Young's modulus values increased. The highest improvement and values of the dynamic Young's modulus with increasing time of water curing exhibited cement-lime render CE3 that had the maximum Young's modulus of $9.2 \mathrm{GPa}$. This material had also high compressive strength, and together with render CE6 highest flexural strength.

- For samples exposed to sulphate solution, initial improvement of the Young's modulus was identified. However, typically from 56 days of samples storing, the elasticity of materials decreased. Certain exception represents render CE3 that improved its Young's modulus from $2.8 \mathrm{GPa}$ (measured for 84 days of sulphate exposure) to $6.6 \mathrm{GPa}$ (140 days stored samples). After 168 days of samples storing in sulphate solution, no increase in the Young's modulus was found, and one can assume its significant decrease for longer time of sulphate attack.

- The lowest values of the dynamic Young's modulus were obtained for render CE4, where no measurable effect of sulphate action was identified. This material of high total open porosity was less sensitive to the changes of porous structure due to the formation of hydration and sulphate corrosion products because of high accumulation capacity of its porous space.

- The X-Ray CT method applied on CE1 samples allowed in dependence on time of samples storing identification of newly formed corrosion products in render porous space. This made the method an effective non-destructive tool for the characterization of porous microstructure of building materials and for monitoring continuous formation of salt corrosion products. Due to its non-destructive character, this method allows studying the time-dependent progression of salt crystallization in a pore space of one and the same sample. Using X-Ray CT, we observed rising of sulphate corrosion products in open pores. First, single surface layer of corrosion substances was identified even in the samples stored in sulphate solution for 28 days. Then we monitored the growing of the corrosion products and their accumulation in porous space. The measured thickness of sulphate salts layer, newly formed in open macropores of render CE1 was growing from the average value of approximately $0.04 \mathrm{~mm}$ after 28 days of exposure to approx. $0.065 \mathrm{~mm}$ after 168 days of samples storing in sulphate solution. In samples exposed six months to the sulphate action, smaller pores (of size up to ca. $0.1-0.2 \mathrm{~mm}$ ) were in most cases fully filled by the corrosion products.

Summarizing the main findings of the presented work, the above given results and comments clearly documented the performance of the researched materials in water and sulphate solution environment. Looking at the durability of tested materials subjected to sulphate attack, the mechanical parameters are of the main importance. During the water storage, the improvement in the mechanical strength was registered. On the other hand, after certain initial improvement of the mechanical resistance of the tested renders exposed to the sulphate environment, decrease of the examined mechanical parameters of the studied materials was identified, except mortar CE6 that maintained its excellent mechanical properties even after long time of exposure to sulphate environment. Also render CE3 maintained its good mechanical characteristics even after the sulphate attack. Here, only slight decrease in the compressive and flexural strength of approx. $3 \%$ between data measured for 140 and 168 days of testing was observed. The biggest deterioration was observed for render CE1, and was caused evidently by the absence of cement in render mix composition. Macroscopically evident extensive damage of CE1 samples corresponded with the crystallization of sulphate corrosion products especially in open pores. As was recognized by the X-Ray CT study, the air voids may be after 168 days exposure practically completely filled by these new mineral phases. Concerning the overall performance of material CE1, one must take into account that this material based on blended metakaolin/ cement binder needs probably longer time for ideal hydration, and remains an open question, what was the amount of metakaolin used. Respecting the measured data for this material, only small amount of metakaolin is expected, and thus formation of more stable $\mathrm{C}-\mathrm{S}-\mathrm{H}$ products was limited. In this case, the main hydrated product was portlandite that is in contact with sulphate solution unstable, and reacts to form $\mathrm{Ca}(\mathrm{SO})_{4}$ hydrates disrupting the material structure.

From the practical point of view, the obtained data gave clear evidence of renders durability in respect to sulphate action, and represents important information for building practise. On the basis of presented results, one can simply recommend renders CE6 and CE3 for renovation of salt laden masonry, and for reconstruction of historical buildings that usually suffer from moisture and salt action. Application of render CE1 for renovation of buildings containing sulphates or for buildings exposed to sulphate action must be avoided because of the low stability of lime hydrates that are more susceptible to the interior volume changes due to the action of chemical agents.

The experimental data can find use also in computational modelling of deterioration process of different kind of renders using models of moisture, heat and salt 
transport, coupled with mechanical problems. Here, the measured data can serve as input material parameters and can be also applied for the models calibration and validation. Using these computational experiments, there will be possible to access the materials durability and to estimate their service life at specific environmental conditions of building structure.

\section{Acknowledgment}

Authors gratefully acknowledge the financial support received from the Czech Science Foundation, under project No 18-07332S.

\section{REFERENCES}

1. Ma L., Zhang Y. (2017): Microstructure-based prediction model for chloride ion diffusivity in hydrated cement paste. Ceramics-Silikáty, 61(2), 110-118. doi:10.13168/ cs.2017.0005

2. Pavlíková M., Pavlík Z., Keppert M., Černý R. (2011): Salt transport and storage parameters of renovation plasters and their possible effects on restored buildings' walls. Construction and Building Materials, 25(3), 1205-1212. doi:10.1016/j.conbuildmat.2010.09.034

3. Lubelli B., van Hees R.P.J., Groot C.J.W.P. (2004): The role of sea slats in the occurrence of different damage mechanisms and decay patterns on brick masonry. Construction and Building Materials, 18, 119-124. doi:10.1016/ j.conbuildmat.2003.08.017

4. CharolaA.E.(2000): Salt in deterioration of porous materials: an review. Journal of American Institute of Conservation, 39, 327-343. doi:10.1179/019713600806113176

5. Menendez B. (2017): Estimation of salt mixture damage on built culture heritage from environmental conditions using ECO-RUNSALT model. Journal of Culture Heritage, 24, 22-30. doi:10.1016/j.culher.2016.11.006

6. Pavlík Z., Fiala L., Maděra J., Pavlíková M., Černý R. (2011): Computational modelling of coupled water and salt transport in porous materials using diffusion advection model. Journal of the Franklin Institute - Engineering and Applied Mathematics, 348(7), 1574-1587. doi:10.1016/j. jfranklin.2010.06.014

7. Gospodinov P., Mironova M., Kazandijev R. (2007): Mechanisms of sulfate ionic diffusion in porous cement based composites. Computers and Concrete, 4(4), 273-284.

8. Lopez-Arce, P., Doehne, E., Greenshields, J., Benavente D., Young D. (2009): Treatment of rising damp and salt decay: the historic masonry buildings of Adelaide, South Australia. Materials and Structures, 42, 827-848. doi:10.1617/s11527-008-9427-1

9. Espinoza-Marzal R.M., Scherer G.W. (2010): Advances in understanding damage by salt crystallization. Accounts of Chemical Research, 43, 897-905. doi:10.1021/ar9002224

10. Franzoni E., Gentlini C., Graziani G., Bandini S. (2014): Towards the assessment of the shear behaviour of masonry in on-site conditions: A study on dry and salt/water contained brick masonry, Construction and Building Materials, 65, 405-416. doi:10.1016/j.conbuildmat.2014.05.002
11. Lei M.F., Peng L.M., Shi C.H., Wang, S.Y. (2013): Experimental study on the damage mechanism of tunnel structure suffering from sulfate attack. Tunnelling and Underground Space Technology, 36, 5-13. doi:10.1016/j.tust.2013.01.007

12. Li Ch., Wu M., Chen Q., Jiang Z. (2018): Chemical and mineralogical alterations of concrete subjected to chemical attacks in complex underground tunnel environments during 20-36 years. Cement and Concrete Composites, 86, 139-159. doi:10.1016/j.cemconcomp.2017.11.007

13. De Weerdt K., Justnes H., Geiker M.R. (2014): Changes in the phase assemblage of concrete exposed to sea water. Cement and Concrete Composites, 47, 53-63. doi:10.1016/j. cemconcomp.2013.09.015

14. Allahverdi A., Mahdavan M. (2013): Durability performance of RFCC spent catalyst-blended Portland cement paste exposed to sea water attack. Ceramics-Silikáty, 57(4), 305-312.

15. Tittarelli F., Moriconi G., Bonazza A. (2008): Atmospheric deterioration of cement plaster in a building exposed to a urban environment. Journal of Culture Heritage, 9(2), 203-206. doi:10.1016/j.culher.2007.09.005

16. Famy C., Taylor H.F.W. (2001): Ettringite in hydration of Portland cement concrete and its occurrence in mature concretes. ACI Materials Journal, 98, 350-356.

17. Crammond N. (2002): The occurrence of thaumasite in modern construction review. Cement and Concrete Composites, 24(4), 393-402. doi: 10.1016/S0958-9465(01) 00092-0

18. Colletta G., Crammond N.J., Swamy R.N., Sharp J.H. (2004): The role of carbon dioxide in the formation of thaumasite. Cement and Concrete Research, 34 (9), 1599-1612. doi:10.1016/j.cemconres.2004.02.024

19. Bensted J. (1999): Thaumasite - background and nature in deterioration of cements, mortars and concretes. Cement and Concrete Research, 21, 117-121. doi:10.1016/S09589465(97)00076-0

20. Barauskas I., Kaminskas R., Liaudanskyté L. (2014): Influence of pozzolana additive on Portland cement in chloride and sulfate environment at low temperatures. Ceramics-Silikáty, 58(2), 138-144.

21. Zhu J., Cao Y., Chen J. (2013): Study on the evolution of dynamic mechanics properties of cement mortar under sulfate attack. Construction and Building Materials, 43, 286-292. doi:10.1016/j.conbuildmat.2013.02.027

22. Lubelli B., Cnudde V., Diaz-Goncalves T., Franzoni E., van Hees R.P.J., Ioannou I., Menendez B., Nunes C., Siedel H., Stefanidou M., Verges-Belmin V., Viles H. (2018): Towards a more effective and reliable salt crystallization test for porous building materials: state of the art. Materials and Structures, 51, 55. doi:10.1617/s11527-018-1180-5

23. EN 1015-3 (1999): Methods of test for mortar for masonry - Part 3: Determination of consistence of fresh mortar (by flow table), CEN.

24. EN 196-1 (2016): Methods of testing cement - Part 1: Determination of strength, CEN.

25. Van Hees R.P.J., Brocken H.J.P. (2001). Interaction of the SBW treatment with $\mathrm{Na}_{2} \mathrm{SO}_{4}, \mathrm{NaCl}$ and $\mathrm{NaNO}_{3}$. in: De Witte E. (ed.): Salt compatibility of surface treatment (SCOST), final report, EU Contract No. ENV4-CT98-0710, pp. 109-119.

26. Lubelli B., van Hees R.P.J., Brocken H.J.P. (2004): Experimental research on hygroscopic behaviour of porous specimens contaminated with salts. Construction 
and Building Materials, 18, 339-348. doi:10.1016/j. conbuildmat.2004.02.007

27. EN 1015-10 (1999): Methods of test for mortar for masonry - Part 10: Determination of dry bulk density of hardened mortar, CEN.

28. Jankovský O., Pavlíková M., Sedmidubský D., Bouša D., Lojka M., Pokorný J., M. Záleská M., Pavlík Z. (2017): Study on pozzolana activity of wheat straw ash as potential admixture for blended cements, Ceramics-Silikáty, 61, 327-339. doi:10.13168/cs.2017.0032

29. Pavlík Z., Keppert M., Pavlíková M., Žumár J., Černý R. (2014): Mechanical, hygric, and durability properties of cement mortar with MSWI bottom ash as partial silica sand replacement. Cement wapno beton, 2, 67-80.

30. EN 1015-11 (1999): Methods of test for mortar for masonry - Part 11: Determination of flexural and compressive strength of hardened mortar, CEN.

31. Mees F., Swennen R., Van Geet M., Jacobs P., eds. (2003). Applications of X-ray computed tomography in the geosciences. Geological Society, London, Special Publication, p. 237.

32. Vavro M., Souček K., Daněk T., Staš L. (2014): Selected non-destructive methods suitable for evaluation of roofing slate. Advanced Materials Research, 923, 63-70. doi:10.4028/www.scientific.net/AMR.923.63

33. Khatib J.M., Wild S. (1998): Sulphate resistance of metakaolin mortar. Cement and Concrete Research, 28(1), 83-92. doi:10.1016/S0008-8846(97)00210-X

34. Clifton J.R., Ponnersheim J.M. (1994). Sulfate Attack of Cementitious Materials: Volumetric Relations and Expansions. NISTR 5390, Building and Fire Research Laboratory, National Institute of Standards and Technology, Gaithersburg, USA.

35. Richardson I.G. (2008): The calcium silicate hydrates. Cement and Concrete Research, 38, 137-158. doi:10.1016/j. cemconres.2007.11.005
36. Mota B., Matschei T., Scrivener K. (2018): Impact of $\mathrm{NaOH}$ and $\mathrm{Na}_{2} \mathrm{SO}_{4}$ on the kinetics and microstructural development of white cement hydration. Cement and Concrete Research, 108, 172-185. doi:10.1016/j.cemconres.2018.03.017

37. Desgranges L., Grebille D., Calvarin G., Chevrier G., Floquet N., Niepce J.-C. (1993): Hydrogen thermal motion in calcium hydroxide: $\mathrm{Ca}(\mathrm{OH})_{2}$. Acta Crystallographica, B49, 812-817. doi: $10.1107 / \mathrm{S} 0108768193003556$

38. Balonis M., Glasser F.P. (2009): The density of cement pastes. Cement and Concrete Research, 39(9), 733-739. doi:10.1016/j.cemconres.2009.06.005

39. Lager G.A., Armbruster T., Rotella F.J., Jorgensen J.D., Hinks D.G. (1984): A crystallographic study of the lowtemperature dehydration products of gypsum, $\mathrm{CaSO}_{4} \cdot 2 \mathrm{H}_{2} \mathrm{O}$, hemihydrate $\mathrm{CaSO}_{4} \cdot 0.5 \mathrm{H}_{2} \mathrm{O}$, and ' $\gamma$ '- $\mathrm{CaSO}_{4}$. American Mineralogist, 69, 910-918.

40. Schofield P.F., Knight K.S., Stretton I.C. (1996): Thermal expansion of gypsum investigated by neutron powder diffraction. American Mineralogist, 81, 847-851. doi: 10.2138/ am-1996-7-807

41. Richardson I.G., Growes G.W. (1997): The structure of calcium silicate, hydrated phases. Cement and Concrete Research, 22, 1001-1010. doi:10.1023/A:1018639232570

42. Fujii K., Kondo W.J. (1983): Heterogeneous equilibrium of calcium silicate hydrate. Journal of the American Ceramic Society, 66, 220-221. doi:10.1039/DT9810000645

43. Thomas J.J., Jennings H.M., Allen A.J. (2010): Relationships between Composition and Density of Tobermorite, Jennite, and Nanoscale $\mathrm{CaO}-\mathrm{SiO}_{2}-\mathrm{H}_{2} \mathrm{O}$. Journal of Physical Chemistry $C, 114,7594-7601$. doi:10.1021/jp910733x

44. Łukowski P., Salih A. (2015): Durability of mortars containing ground granulated blast-furnace slag in acid and sulphate environment. Procedia Engineering, 108, 47-54. doi:10.1016/j.proeng.2015.06.118

45. Rozière E., Loukili A., El Hachem R. (2008): Durability of concrete exposed to leaching and external sulphate attacks. Cement and Concrete Research, 9, 1188-1198. doi:10.1016/ j.cemconres.2009.07.021 